\title{
Seismic Capacity Design of RC frames and environment-induced degradation of materials: Any concern?
}

\author{
Enzo Martinelli a,*, Emrah Erduran ${ }^{\mathrm{b}, 1}$ \\ ${ }^{a}$ Department of Civil Engineering, University of Salerno, Via Ponte don Melillo, 84084 Fisciano (SA), Italy \\ ${ }^{\mathrm{b}}$ NORSAR Stiftelsen, Gunnar Randers vei 15, N-2007 Kjeller, Norway
}

\section{A R T I C L E I N F O}

\section{Article history:}

Received 10 July 2012

Revised 18 February 2013

Accepted 21 February 2013

Available online 12 April 2013

\section{Keywords:}

Reinforced concrete

Degradation

Carbonation

Corrosion

Seismic design

Capacity Design

\begin{abstract}
A B S T R A C T
The Capacity Design approach emerged in the second half of the last century and is currently adopted by all the modern codes of practice for construction in seismic areas. It is based on the fundamental concept that the structure under consideration should not exhibit brittle failure modes, as brittle members or mechanisms are designed to be stronger than the maximum expected stresses they possibly get from the adjacent ductile members or mechanisms. This condition is generally imposed at the design stage without considering any degradation in material properties possibly due to the environmental agents. Although structural codes for RC structures usually provide practitioners with sound criteria intended at limiting the development of detrimental degradation phenomena, they have been never assessed against the possible loss in over-strength of brittle failure modes due to environment-induced degradation phenomena possibly occurring during the service life of the structure.

This study aims to answer the question stated in the title and, in the authors' knowledge, is one of the first attempts to embrace two traditionally distant research fields, such as Earthquake Engineering and Material Science. Thus, the paper investigates the time evolution of the possible failure modes in beams due to the premature degradation of steel stirrups and longitudinal reinforcement during the service life of RC structures. Both material properties and environmental conditions are taken into account to assess durability and structural safety in seismically designed RC beams and the possible consequences of material degradation on their expected failure modes under seismic actions.
\end{abstract}

(c) 2013 Elsevier Ltd. All rights reserved.

\section{Introduction}

Seismic design of reinforced concrete (RC) frames based on the concept of Capacity Design emerged in the second half of the last century and was recently adopted as a fundamental inspiring principle in the most up-to-date codes of practice for construction in seismic areas. Preventing brittle failure modes by providing critical members with strength higher than the maximum expected stresses induced by the adjacent ductile members or mechanisms is the key concept of this design philosophy. For instance, in reinforced concrete (RC) frames, both beams and columns should be designed to be stronger in shear than in bending [1]. This approach is based on designing transverse reinforcement (mainly controlling shear strength in members) against the maximum shear stresses possibly induced by the achievement of ultimate bending moments at the beam end sections. This condition is generally imposed at the design stage and the possible randomness in mechanical proper-

\footnotetext{
* Corresponding author. Tel.: +39 08996 4098; fax: +39 089964045

E-mail addresses: e.martinelli@unisa.it (E. Martinelli), emrah@norsar.no (E. Erduran).

1 Tel.: +47 63805917 (Office).
}

ties of materials is also taken into account by introducing suitable values of the so-called "over-strength" ratios adopted for amplifying the design values of ultimate bending strength to estimate their expected ones [2]. However, no specific attention is paid to any degradation effect potentially induced by environmental actions, possibly resulting in corrosion of reinforcing steel and cracking/spalling of the concrete cover [3]. Although design codes for RC structures usually provide practitioners with sound criteria intended at limiting the development of detrimental degradation phenomena [4], their efficiency in guaranteeing sufficient overstrength levels against the brittle failure mechanisms to ensure a ductile behaviour under a major earthquake (possibly occurring during its service life) has never been assessed. As a matter of fact, since the thickness of concrete cover is one of the key parameters controlling the possible initiation of steel bar corrosion [5], transversal stirrups in RC beams are potentially more exposed to environmental degradation, as they are usually protected by concrete covers thinner than the corresponding longitudinal bars. Thus, their possible degradation in seismically designed RC structures could not only undermine aesthetics and functionality of members, but even jeopardise the structural safety and turn its seismic response into a more brittle behaviour. 
This study is intended at providing readers with quantitative measures of this possible unfavourable evolution of the structural behaviour depending on both material properties and environmental conditions. Under this standpoint, it represents one of the first attempts to embrace two traditionally distant research fields such as Earthquake Engineering and Material Science. As a matter of fact, few studies are available to date in the scientific literature to address the analysis of the structural consequences of material degradations, as this topic is more often investigated by material scientists [6]. Recent contributions have been presented on the influence of climate change as a possible driving force of material degradation and safety reduction in civil engineering structures and infrastructures [7]. However, the definition of consistent protocols to analyse RC frames affected by degradation phenomena is still in progress [8].

Due to the wide variety of the expected environmental actions considered in the so-called "Exposure Classes" of possible interest, the present study is limited to the case of carbonation-induced degradation phenomena, possibly arising in rather common exposure classes (i.e. XC1 to XC4) according to the definition reported in [4]. Duly simplified models taken from the scientific literature will be adopted for simulating the time evolution of carbonation in concrete [9] and its possible consequences in terms of reinforcement corrosion and cover cracking/spalling $[3,10]$. The possible influence of environmental conditions on the development of carbonation [11] as well as the effect of the concrete quality on the steel corrosion rates will be taken into account [12]. Thus, a set of analytical models currently available in the scientific literature will be consistently employed to define the time evolution of the residual sections of both longitudinal and transversal rebars with the aim of simulating the effect of corrosion according to a simplified and widely accepted model introduced by Tuutti [13].

This paper addresses the possible influence of material degradation on the seismic response of structures designed according to the most recent seismic design codes and, particularly, focuses on quantifying the possible transition from ductile failure modes in beams (ensured by the above mentioned Capacity Design principles) to brittle ones due to the degradation of transverse reinforcement. Section 2 outlines a series of analytical models intended at describing the time evolution of damage phenomena related to carbonation-induced corrosion. Such models were selected from a wide set of proposals currently available in the scientific literature and define a consistent protocol for describing how the degradation phenomena modifies the geometric and mechanical properties that are of interest in seismic analysis of structures. Section 3 reformulates the Capacity Design approach in a general dimensionless form intended at performing a parametric analysis which aims to quantify the time evolution of the design margin against brittle failure of beams during the service life of RC frames. Section 4 introduces such a parametric analysis, whose key results are reported and commented in Section 5.

In the authors' opinion, the application of material degradation models in seismic engineering is one of the key novel aspects proposed by the present paper that aims to achieve the following objectives:

- formulating a comprehensive protocol to implement the degradation models, often formulated at the material level, and scale them up to the structure level to be efficiently employed in seismic analyses;

- pointing out if members of RC structures designed according to the latest seismic design provisions can be possibly affected by a ductile-to-brittle failure mode transition induced by material degradation taking place during their service life and affecting both transverse and longitudinal reinforcements;
- determining the time of this possible transition and pointing out the most critical environmental conditions and material properties that potentially lead to such a transition.

Finally, this paper aims at answering the question asked in its title. Particularly, the proposed analyses are intended at understanding if environment-induced degradation phenomena can actually affect the preservation of the "strength hierarchy" imposed in seismic design of concrete structures. Should this be the case, the proposed results will pave the way for a complete probabilistic assessment for the member behaviour, which is part of the future development of the present research.

\section{Outline of models for carbonation-induced degradation of RC members}

This section outlines a selection of analytical models currently available in the scientific literature to simulate the extents and the time evolution of carbonation, corrosion and concrete cover degradation. Subsection 2.1 summarises the details of a recent proposal for simulating carbonation diffusion in concrete members and, then, subsections 2.2 and 2.3 define the above mentioned limit states. It is worth noting that these subsections are not intended as a thorough State-of-the-Art report, which can be found in [3]. Instead, they are aimed at defining a consistent protocol to identify the well-known Tuutti diagram (Fig. 1) that conceptually describes the evolution of material degradation and defines the three following limit states [9]:

- depassivation;

- cracking of concrete cover;

- spalling of concrete cover.

Finally, further relevant aspects related to the consequences of bar corrosion are mentioned in Section 2.4.

\subsection{Carbonation-induced depassivation of reinforcing bars}

One of the most recent and consistent models to simulate the evolution of carbonation through the cortical layer of concrete in $\mathrm{RC}$ members is based on the following analytical relationship [9] (Fig. 2):

$x_{c}(t)=\sqrt{2 \cdot k_{e} \cdot k_{c} \cdot R_{\mathrm{NAC}, 0}^{-1} \cdot C_{s}} \cdot \sqrt{t} \cdot W(t)$

where $t$ is the time in years (after casting and curing), $x_{c}(t)$ is the current depth of the carbonated concrete layer, $k_{e}$ is the

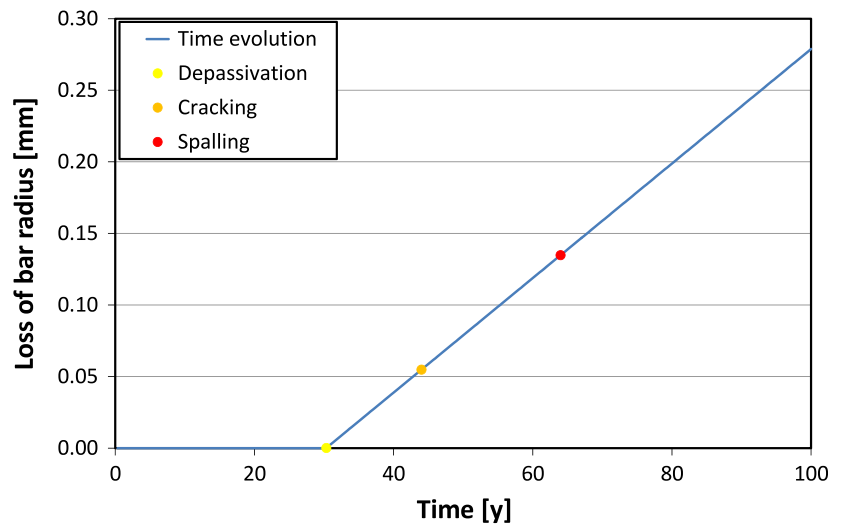

Fig. 1. Time evolution of corrosion and relevant limit states considered in this study. 


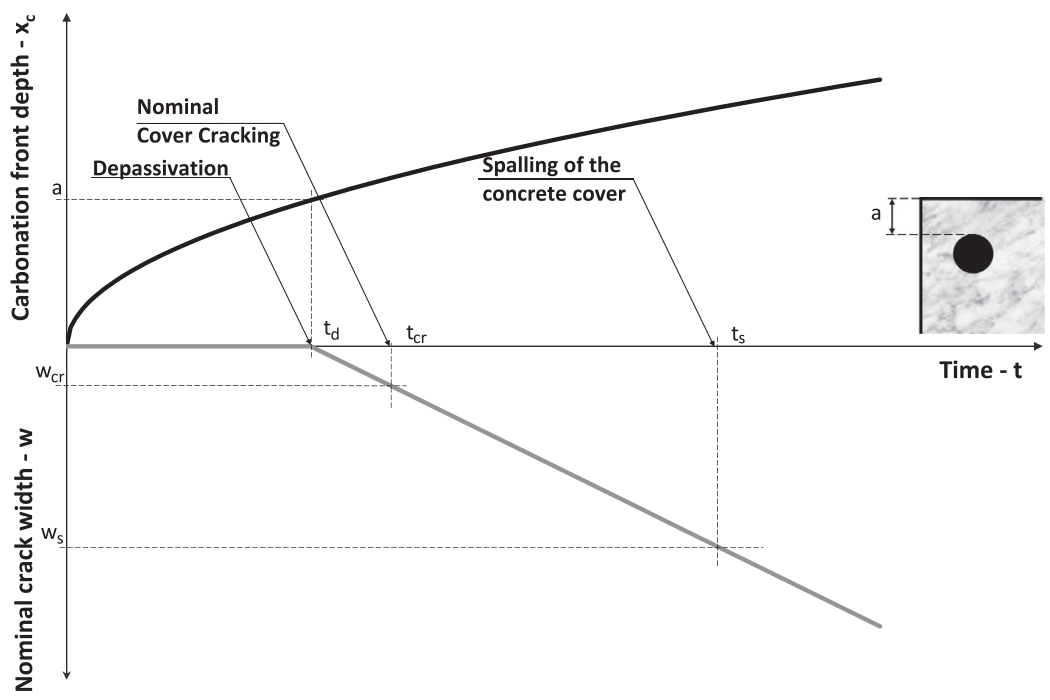

Fig. 2. At-a-glance overview of the key carbonation-induced degradation phenomena considered in this study.

environmental factor, $k_{c}$ is the "execution transfer parameter", $R_{\mathrm{NAC} 0}^{-1}$ is the inverse of carbonation resistance, $C_{s}$ is the relevant $\mathrm{CO}_{2}$ concentration and, finally, $W(t)$ is the so-called weather function. The environmental function $k_{e}$ simulates the possible influence of relative humidity, $\mathrm{RH}$, on the rate of carbonation. Since experiments are generally conducted at $\mathrm{RH}_{\text {ref }}=65 \%$ (and temperature $T=20^{\circ} \mathrm{C}$ ), $k_{e}$ is defined as a correction factor depending on the actual relative humidity, $\mathrm{RH}_{\text {real, }}$, whose aleatoric variability could, in principle, be described through either Beta or Weibull distributions):

$k_{e}=\left[\frac{1-\left(\frac{\mathrm{RH}_{\text {real }}}{100}\right)^{f_{c}}}{1-\left(\frac{\mathrm{RH}_{\mathrm{ref}}}{100}\right)^{f_{c}}}\right]^{g_{c}}$,

where $f_{c}$ and $g_{c}$ can be calibrated using experimental results: in absence of specific studies, the values of 2.5 and 5.0 can be adopted for $f_{c}$ and $g_{c}$, respectively [9]. Moreover, the execution transfer parameter $k_{c}$ is related to the time of curing $t_{c}$ through the following correlation:

$k_{c}=\left(\frac{t_{c}}{7}\right)^{b_{c}}$

where $b_{c}$ should be derived by a regression analysis. A normal distribution for $b_{c}$ characterised by a mean value of -0.567 and a standard deviation of 0.024 is proposed in [14].

A key role in controlling the rate of propagation of the carbonated front is played by the inverse of the carbonation resistance $R_{\mathrm{NAC}, 0}^{-1}$ [in $\mathrm{mm}^{2} / \mathrm{s} /\left(\mathrm{kg} / \mathrm{m}^{3}\right)$ ]. This quantity is generally obtained through accelerated tests aimed at measuring the corresponding value $R_{\mathrm{ACC}, 0}^{-1}$, which is mostly higher than $R_{\mathrm{NAC}, 0}^{-1}$ and mainly affected by the water/cement (or water/binder) ratio, as it depends on the actual porosity and permeability of concrete. The following linear relationship can be, then, assumed to compute $R_{\mathrm{NAC}, 0}^{-1}$ :

$R_{\mathrm{NAC}, 0}^{-1}=\left(k_{t} \cdot R_{\mathrm{ACC}, 0}^{-1}+\varepsilon_{t}\right)$

where the terms $k_{t}$ and $\varepsilon_{t}$ can be statistically represented by two independent normal distributions. Specifically, the former variable will be described by a mean value of 1.25 and a standard variation of 0.35 , whereas the latter by $315.5 \mathrm{~mm}^{2} / \mathrm{s} /\left(\mathrm{kg} / \mathrm{m}^{3}\right)$ and $48 \mathrm{~mm}^{2} / \mathrm{s} /$ $\left(\mathrm{kg} / \mathrm{m}^{3}\right)$, respectively. The experimental values of $R_{\mathrm{ACC}, 0}^{-1}$ reported in [9] depending on water/binder ratio, for different binder types and blends, will be assumed in the analyses proposed in the present paper (Table 1 ).
Table 1

Values of $R_{\mathrm{ACC}, 0}^{-1}$ as a function of cement type and water/cement ratio [9].

\begin{tabular}{lllllll}
\hline Cement type & \multicolumn{6}{l}{$R_{\mathrm{ACC}, 0}^{-1}\left[10^{-11}\left(\mathrm{~m}^{2} / \mathrm{s}\right) /\left(\mathrm{kg} / \mathrm{m}^{3}\right)\right]$} \\
\cline { 2 - 7 } & \multicolumn{1}{l}{$\mathrm{w} / \mathrm{c}$} & & & & \\
\cline { 2 - 7 } & 0.35 & 0.40 & 0.45 & 0.50 & 0.55 & 0.60 \\
\hline CEM I 42.5 R & n.a. & 3.1 & 5.2 & 6.8 & 9.8 & 13.4 \\
CEM III/B 42.5 & n.a. & 8.3 & 16.9 & 26.6 & 44.3 & 80.0 \\
\hline
\end{tabular}

Finally, as far as the $\mathrm{CO}_{2}$ concentration (in $\mathrm{kg} / \mathrm{m}^{3}$ ) is concerned, the ordinary atmosphere value can be represented by a normal distribution with $0.00082 \mathrm{~kg} / \mathrm{m}^{3}$ mean value and $0.0001 \mathrm{~kg} / \mathrm{m}^{3}$ standard deviation. Moreover, the weather function $W(t)$ is intended at simulating the effects of driving rains on carbonation of the member under consideration. $W(t)$ can be expressed as:

$W(t)=\left(\frac{t_{0}}{t}\right)^{\frac{\left(p_{S R} \cdot T o W\right)^{b_{W}}}{2}}$

where $p_{S R}$ is the probability of driving rain (i.e., the distribution of wind direction during rain events) in $t_{0}=28$ days $=0.0767$ years, ToW the time of wetness (defined as the annual frequency of days with rainfall $h_{N d} \geqslant 2.5 \mathrm{~mm}$ ) and, $b_{w}$, a normally distributed variable with mean value 0.446 and standard deviation 0.163 .

A brief overview of the above mentioned models and parameters is summarised above, though several details had to be omitted due to space constraints. The reader is, thus, referred to fib [9] for further relevant information on such aspects.

\subsection{Carbonation-induced depassivation and corrosion of reinforcing bars}

The equations reported in Section 2.1 outline a model for describing the time evolution of carbonation depending on both environmental exposure and relevant material properties. Thus, it can be employed for detecting if the carbonation front penetrated throughout the whole concrete cover thickness, " $a$ " and, then, the outer steel bars are exposed to corrosion as a result of the reduction in $\mathrm{pH}$ of the surrounding concrete induced by the carbonation reaction. Since both $x_{c}(t)$ and the concrete cover thickness could, in principle, be defined in statistical terms, the following limit state function: 
$g_{d}\left(a, x_{c}(t)\right)=a-x_{c}(t)$

represents the depassivation condition in case $g_{d}\left(a, x_{c}(t)\right)$ takes a non-positive value. In Eq. (6) $x_{c}(t)$ can be computed through Eqs. (1)-(5), while the concrete cover can be represented by an aleatoric variable with lognormal distribution around the nominal value and a standard deviation in the order of the common execution tolerance in construction sites of concrete structures (i.e., $10 \mathrm{~mm}$, according to [9]). The time $t_{d}$ at which $g_{d}\left(a, x_{c}\left(t_{d}\right)\right)=0$ can be, then, assumed as the time for steel reinforcement depassivation.

Once the depassivation has occurred, corrosion can start developing in the reinforcing bars. Corrosion is a rather complex phenomenon, which can be influenced by several parameters and conditions [6]. However, a simplified, though well-established, relationship is adopted to quantify the reduction in bar radius $x_{\text {loss, },}\left(t_{p}\right)$ after a given time of propagation, $t_{p}=t-t_{d}$. It is based on the assumption of a constant rate of corrosion, $V_{\text {corr }}$ [13], which basically depends on the actual exposure class [4]. Reference values of both mean and standard deviation of $V_{\text {corr }}$ for each one of the above mentioned exposure classes are available in a recent and comprehensive document [3]. Thus, the value of $x_{\text {loss, }}\left(t_{p}\right)$

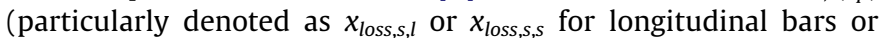
transverse stirrups, respectively) can be expressed as follows:

$x_{\text {loss }, S}\left(t_{p}\right)=V_{\text {corr }} \cdot t_{p} \cdot w_{t}$

where the coefficient $w_{t}$ takes into account the time of wetness and is also quantified in [3]. Table 2 summarises the values of both $V_{\text {corr }}$ and $w_{t}$ for the exposure classes of interest for this paper. Based on the above models, the value of the (equivalent) bar diameter $\phi\left(t_{p}\right)$ at time $t_{p}$ can be defined as follows:

$\phi\left(t_{p}\right)=\phi_{0}-\alpha \cdot x_{\text {loss }, \text { S }}\left(t_{p}\right)$

where $\alpha$ is a shape coefficient which takes into account the consequences of the actual development of corrosion on the bar diameter [15] and $\phi_{0}$ is the initial bar diameter. Since a rather homogeneous development is generally observed in carbonation-induced corrosion, $\alpha=2$ will be assumed in this study. However, it is worth highlighting that localised (pitting) corrosion can occur in some conditions and higher values of $\alpha$ (even up to 10 ) should be adopted to simulate such cases [3].

\subsection{Cracking and spalling of the concrete cover}

The development and evolution of corrosion in steel bars within a reinforced concrete section leads to the increase of their volume and, in turn, results in the possible cracking and, later, spalling of the concrete cover. The accurate simulation of this degenerative phenomenon (and the possible definition of the equivalent thickness $x_{\text {loss }, \text { }}$ of the concrete layer which has been lost at the time $t$ ) is quite complicated because it is characterised by the joint actions of the volume evolution in the corroding bar and the tensile/splitting strength of concrete [10]. Thus, several advanced models are currently available for quantifying the crack width $w\left(t_{p}\right)$ induced by bar corrosion in the concrete cover [9]. However, for the sake

\section{Table 2}

Steel reinforcement corrosion-related parameters according to the model presented in [3].

\begin{tabular}{llllll}
\hline \multirow{2}{*}{ Exposure class } & \multicolumn{2}{l}{ Parameter } & & \\
\cline { 2 - 3 } & \multicolumn{2}{l}{$V_{\text {corr }}(\mathrm{mm} / \mathrm{y})$} & & $w_{t}$ & \\
\cline { 2 - 3 } \cline { 5 - 6 } & Mean & Stand. dev. & & Mean & Stand. dev. \\
\hline XC1 & 0.000 & - & 0.0 & - \\
XC2 & 0.004 & 0.003 & & 1.0 & - \\
XC3 & 0.002 & 0.001 & & 0.5 & - \\
XC4 & 0.005 & 0.003 & & 0.75 & - \\
\hline
\end{tabular}

of simplicity, and in line with the aim of the present study, a simple method based on a correlation between $x_{\text {loss,s }}\left(t_{p}\right)$ and $w\left(t_{p}\right)$ is considered [3] (Fig. 2):

$$
\begin{aligned}
w\left(t_{p}\right) & =0.05+\beta \cdot\left[x_{\text {loss }, S}\left(t_{p}\right)-x_{0}\right] \text { with } 0.0 \mathrm{~mm} \leqslant w\left(t_{p}\right) \\
& \leqslant 1.0 \mathrm{~mm}
\end{aligned}
$$

where $\beta$ is a coefficient depending on the position of the bar under consideration ( $\beta=0.010$ can be reasonably assumed) and $x_{0}$ is a parameter related to the cover-to-diameter ratio and the splitting strength of concrete:

$x_{0}=83.8+7.4 \cdot \frac{a}{\phi}-22.6 \cdot f_{c, s p}$ in $\mu \mathrm{m}$

As a matter of principle, the limit states of cracking control and spalling could be defined through the two following functions, respectively:

$g_{c r}\left(t_{p}\right)=w_{c r}-w\left(t_{p}\right)$

and

$g_{s}\left(t_{p}\right)=w_{s}-w\left(t_{p}\right)$

where $w_{c r}$ and $w_{s}$ are the crack widths corresponding to cracking and spalling, respectively. In the present study, a value $w_{c r}=0.2 \mathrm{~mm}$ is considered according to EN 1992-1-1:2005 [4], whereas $w_{s}=1.0-$ $\mathrm{mm}$ is taken from the scientific literature as a crack width corresponding to cover spalling [3,9]. Thus, two time values $t_{c r}$ and $t_{s}$ can be, in principle, defined in correspondence of the two above mentioned corresponding values $w_{c r}$ and $w_{s}$ of the nominal crack width.

As a final comment, it is worth highlighting the key role of the concrete cover thickness $a$ in controlling the degradation phenomena driven by carbonation and resulting in cracking and spalling of concrete (Fig. 2). Particularly, it controls the occurrence of rebar depassivation which triggers the other degradation phenomena. Since corrosion in reinforcing bars is supposed to begin at $t_{d}$, the linear relationship in Eq. (9) can be assumed to describe the time evolution of the nominal crack widths resulting in concrete cover from the expansion of the steel oxidation products. Moreover, Fig. 3 further clarifies the time evolution of degradation phenomena in both steel bars and concrete cover:

- a linear reduction of the bar radius is assumed according to Eqs. (7) and (8);

- the total concrete cover $d^{\prime}=a+\phi / 2$ is supposed to get progressively lost during the cracking phenomenon: the linear evolution in time represented in Fig. 3 for the parameter $x_{\text {loss,c }}(t)$ between $t_{c r}$ and $t_{s}$ is an assumption of this paper, as it satisfies the initial (no loss before $t_{c r}$ ) and final state (all the concrete cover is lost after $\left.t_{s}\right)$ :

$x_{\text {loss }, c}(t)=\left\{\begin{array}{cc}0 & 0 \leqslant t<t_{c r}<0 \\ \frac{w\left(t_{p}=t-t_{d}\right)-w_{c r}}{w_{s}-w_{c r}} \cdot d^{\prime} & t_{c r} \leqslant t<t_{s} \\ d^{\prime} & t>t_{s}\end{array}\right.$

\subsection{Insights on the behaviour of RC members with corroded bars}

Corrosion of a steel bar significantly modifies both the mechanical behaviour of steel and its interaction with concrete. As far as the first aspect is concerned, reduction in ductility has been observed in corroded steel bars. As a rule of thumb, available data on non-monotonic tensile tests allow to figure out a reduction in ultimate elongation in the same order of magnitude with the section (or weight) reduction of bars due to corrosion [3]. The study of the cyclic performance of RC members with corroded steel bars 


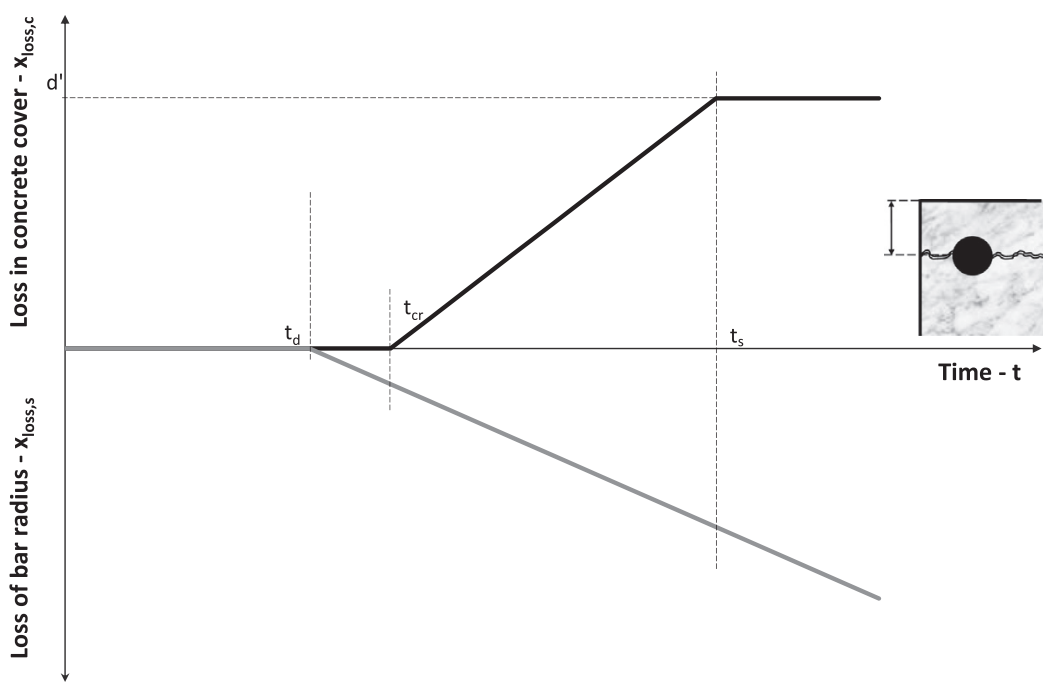

Fig. 3. Time evolution of corrosion and loss of concrete cover as modelled in the present study.

was recently approached as one of the most relevant topics for seismic assessment of existing RC frames [16].

Regarding the degradation of steel-concrete bond interaction, corrosion can deeply modify pressure and friction at the steel-concrete interface [17] and significantly affect their interaction, even before cover spalling, whereas no significant bond can be considered after spalling.

As a matter of principle, both phenomena should be considered in simulating the response of RC structures under seismic action. However, they will generally be neglected in this article, as this study evaluates the effect of corrosion on the shear and bending capacity of RC beams and neither reduction in the steel ultimate elongation nor bond strength have a significant effect on the shear or bending capacity of RC beams, as both phenomena become influential once these capacities are exceeded. On the contrary, these two aspects would be of utmost importance in any analysis aimed at evaluating deformation-related aspects (i.e., momentcurvature diagrams), as they are directly influenced by the bond-slip relationship between steel bars and concrete as well as the ultimate elongation capacity of steel bars. Further insights on the effect of environment-induced material degradation and the possible criteria to consider them in evaluating the strength of $\mathrm{RC}$ members can also be found in [18].

\section{Dimensionless formulation of Capacity Design relationships for beams in RC frames}

This section recalls the key analytical relationships defining shear over-strength as a key aspect of Capacity Design of RC structures. Particularly, the formulation is limited to the case of beams (but could be similar for columns) and reported in dimensionless form with the aim of covering an ideally wide range of cases of practical relevance. The proposed relationships are aimed at explaining how material degradation models outlined in Section 2 are actually employed in the present study. Moreover, the proposed dimensionless formulation allows for a general application of the well-known Capacity Design relationships to a wide range of structural members characterised by the relevant nondimensional parameters.

\subsection{Definition of the key geometric and mechanical parameters}

The beam under consideration has a rectangular cross section of width $b$, depth $h$, design concrete cover $d^{\prime}$ and effective depth $d=h-d^{\prime}$ (Fig. 4). It is reinforced by top and bottom longitudinal reinforcing bars whose total areas are denoted as $A_{s, t}$ and $A_{s, b}$, respectively. Both top and bottom reinforcements include a certain number of bars with the same diameter $\phi$ placed at a concrete cover " $a$ " from top and bottom sides of the beam. The beam has a span length $L$ and the same cross-section at both ends. Transverse reinforcement is considered as a two-branch steel stirrup with a diameter $\phi_{s}$, area $A_{s}$ and spacing in the critical zones is $s$.

The strengths of materials are described by their characteristic values. Thus, concrete is described by $f_{c k}$ and the corresponding design value $f_{c d}$ is obtained according to the EN-1992-1-1:2005 [4] provisions by assuming a partial safety factor $\gamma_{c}=1.5$ :

$f_{c d}=\frac{0.85 \cdot f_{c k}}{\gamma_{c}}$

whereas the design value steel yielding stress $f_{\text {sd }}$ (of both longitudinal and transverse reinforcement) is defined according to similar provisions and dividing the characteristic value, $f_{s k}$, by $\gamma_{s}=1.15$.

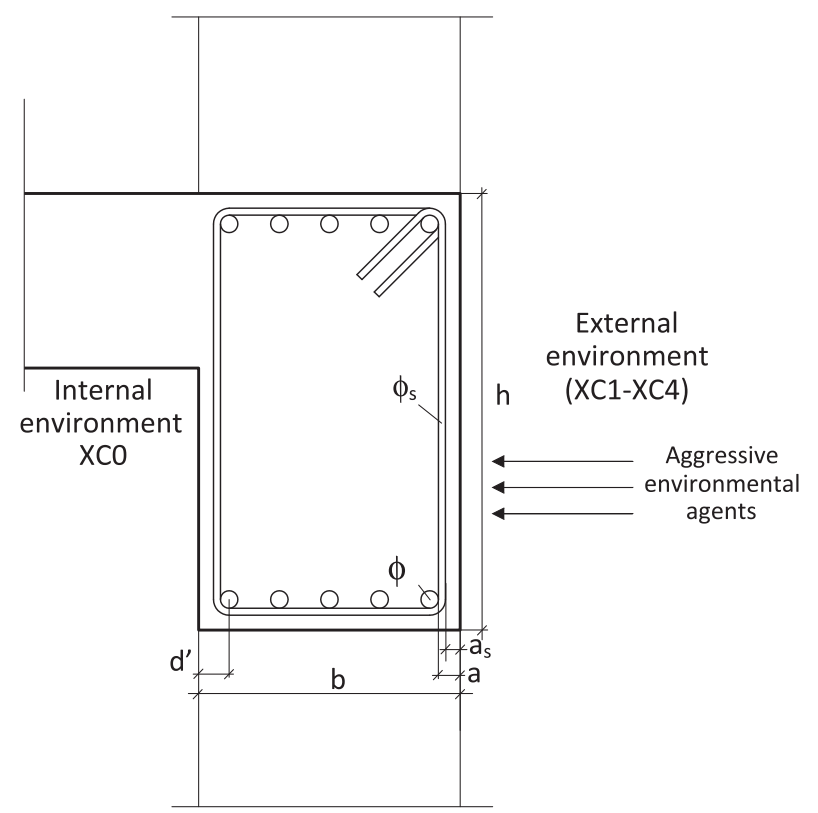

Fig. 4. Exposure conditions and relevant geometrical parameters of the section under consideration. 


\subsection{Capacity Design for shear/bending strength hierarchy}

Under seismic shaking, the ultimate bending strength is expected to be achieved at both beam ends and, consequently, the resulting maximum value of shear force can be estimated as follows:

$V_{E d}=\frac{q_{Q P} L}{2}+\gamma_{R d} \cdot \frac{M_{R d}^{(+)}+M_{R d}^{(-)}}{L}$,

where $q_{Q P}$ is the distributed transverse load due to gravity loads, $\gamma_{R d}$ is the over-strength ratio mentioned in Section 1, whereas $M_{R d}^{(+)}$and $M_{R d}^{(-)}$are the design values of the ultimate bending moments at end sections (positive and negative, respectively). The latter can easily be expressed in terms of the available longitudinal reinforcement:

$M_{R d}^{(+)}=\zeta^{(+)} A_{s, b} f_{s d} h \approx 0.85 \cdot A_{s, b} f_{s d} h, M_{R d}^{(-)}=\zeta^{(-)} A_{s, t} f_{s d} h \approx 0.85 \cdot A_{s, b} f_{s d} h$.

where $\zeta$ factors depend on the actual length of the internal lever arm.

According to the equivalent-strut model, the slope $\beta$ of struts can be evaluated by imposing that the so-called shear-compression design strength $V_{R c d}$ is equal to $V_{E d}$. The former can be expressed as follows (EN 1992-1-1:2005 [4]):

$V_{R c d}=0.9 \cdot d \cdot b \cdot \alpha_{c} \cdot \frac{f_{c d}}{2} \cdot \frac{\operatorname{ctg} \alpha+\operatorname{ctg} \beta}{1+\operatorname{ctg}^{2} \beta}$,

where $\alpha_{c}=1$ for members in bending and $\alpha$ is the angle between the beam axis and the stirrup plane. After few mathematical transformations, the following closed form can be derived for the case of beams with stirrups perpendicular to the beam axis $\left(\alpha=90^{\circ}\right)$ :

$\overline{\operatorname{ctg} \beta}=\frac{0.225 \cdot d \cdot b \cdot f_{c d}}{V_{E d}} \cdot\left[1+\sqrt{1-\left(\frac{V_{E d}}{0.225 \cdot d \cdot b \cdot f_{c d}}\right)^{2}}\right]$

However, the $\overline{\operatorname{ctg} \beta}$ should be limited between 1.0 and 2.5 according to a specific code provision [4]. Finally, the stirrup spacing s can be designed by adopting the Eq. (18) with the above mentioned limitations in the relationship, which defines the sheartension design strength $V_{R s d}$ [4]:

$V_{R s d}=0.9 \cdot d \cdot \frac{A_{s} \cdot f_{s d}}{s} \cdot \overline{\operatorname{ctg} \beta}$

after imposing $V_{R s d}=V_{E d}$, the maximum spacing of stirrups can be determined:

$s=0.9 \cdot d \cdot \frac{A_{s} \cdot f_{s d}}{V_{E d}} \cdot \overline{\operatorname{ctg} \beta}$

Thus, Eqs. (15)-(20) can be employed to design stirrup spacing. In this study, a general dimensionless form of such equations will be employed for the sake of generality after having defined the following non-dimensional quantities:

- non-dimensional shear force:

$v_{E d}=\frac{V_{E d}}{b h f_{c d}}$

- non-dimensional resisting moment:

$\mu_{E d}=\frac{M_{R d}}{b h^{2} f_{c d}}$

- non-dimensional transverse load:

$\theta_{Q P}=\frac{q_{Q P} L}{b h f_{c d}}$

- longitudinal bar ratio:

$\rho=\frac{A_{s, t}}{A_{s, b}}$
- transverse-to-longitudinal bar ratio:

$\rho_{s}=\frac{A_{s}}{A_{s, b}}$

- mechanical ratio of stirrups:

$\omega_{s}=\frac{A_{s} f_{s d}}{b h f_{c d}}$

- mechanical ratio of bottom longitudinal bars:

$\omega=\frac{A_{s, b} f_{s d}}{b h f_{c d}}$

- span-length-to-depth ratio:

$\lambda=\frac{L}{h}$

- effective-to-nominal depth ratio:

$\delta=\frac{d}{h}$.

The value of the $s / h$ ratio can generally be determined by properly employing Eqs. (15)-(20) with the non-dimensional parameters defined by (21)-(29) and, then, the actual value $s_{\text {eff }} / h$ of spacing-to-depth ratio can be chosen by taking into account possible limitations (i.e., $s \leqslant h / 4$ as stated in [2] for the so-called "critical zones" of beams):

$\frac{S_{\text {eff }}}{h}=\min \left\{0.9 \cdot \delta \cdot \frac{\omega_{s}}{v_{E d}} \cdot \overline{\operatorname{ctg} \beta} ; \frac{1}{4}\right\}$.

The corresponding shear strength can be determined by imposing the equality between design-values of shear-compression $V_{R c d}$ (17) and shear-tension $V_{R s d}(19)$ :

$1.0 \leqslant \overline{\overline{\operatorname{ctg} \beta}}=\sqrt{\frac{1}{2} \cdot \frac{A_{s, b}}{A_{s}} \cdot \frac{b h f_{c d}}{A_{s, b} f_{s d}} \cdot \frac{s_{e f f}}{h}}-1 \leqslant 2.5$

and, finally,

$V_{R d}=0.9 \cdot \frac{d}{S_{\text {eff }}} \cdot A_{s} f_{s d} \cdot \overline{\overline{\operatorname{ctg} \beta}}$.

It is worth noting that $\overline{\operatorname{ctg} \beta}$ in Eq. (18) simply derives from the equality between shear force $V_{E d}$ and the corresponding value of the compression shear strength $V_{R c d}$. Conversely, $\overline{\operatorname{ctg} \beta}$ takes also into account the effect of both choosing "round" values for $s_{\text {eff }} / \mathrm{h}$ ratio and complying with the code limitations described in Eq. (31).

Finally, the objective of the Capacity Design principle is achieved if the shear strength $V_{R d}$ in Eq. (32) is higher than the shear stresses $V_{E d}$ evaluated under seismic actions according to (15). More generally, these two quantities can be expressed in the following dimensionless forms:

$v_{E d}=\frac{V_{E d}}{b h f_{c d}}=\frac{\theta_{Q P}}{2}+\gamma_{R d} \cdot\left(\mu_{R d}^{(+)}+\mu_{R d}^{(-)}\right) \cdot \frac{h}{L}$

$\approx \frac{\theta_{Q P}}{2}+0.85 \cdot \gamma_{R d} \cdot(1+\rho) \cdot \omega \cdot \frac{h}{L}$,

$v_{R d}=\frac{V_{R d}}{b h f_{c d}}=0.9 \cdot \delta \cdot \frac{h}{S_{\text {eff }}} \cdot \rho_{s} \cdot \omega \cdot \overline{\overline{\operatorname{ctg} \beta}}=0.9 \cdot \delta \cdot \frac{h}{S_{\text {eff }}} \cdot \omega_{s} \cdot \overline{\overline{\operatorname{ctg} \beta}}$.

The term $v_{E d}$ corresponds to the initial (design) value of the maximum potential shear action induced by the formation of two plastic hinges at the beam ends; correspondingly, $v_{R d}$ is the initial design shear strength.

\subsection{Time evolution due to degradation phenomena}

Since this study is aimed at assessing if and how degradation phenomena could actually affect shear capacity and reduce the design safety margin against brittle failure of beams, the time 
evolution of $v_{E d}$ and $v_{R d}$ should be simulated by taking into account the consequences of corrosion possibly occurring in stirrups and longitudinal bars and, then, affecting some of the relevant non-dimensional parameters considered in Eqs. (33) and (34). Particularly, the interest of this study is motivated by the fact that, due to obvious constructional constraints, stirrups are generally closer to the concrete surface than the longitudinal bars, and thus, more exposed to corrosion effects.

The models reported in Section 2 for describing degradation phenomena in RC members can be effectively employed for analysing the time evolution of the design safety margin against the shear failure of beams under seismic actions due to possible corrosion in stirrups. The critical case of a beam exposed to aggressive environment on only one of the lateral faces (whereas the other faces are either sheltered by other non-structural components or in XCO condition according to the exposure classes defined in [5]) is considered in this study. The case under consideration is represented in Fig. 4 which points out that, in principle, only one of the steel stirrup branches and one of the external longitudinal bars are exposed to the degradation phenomena, whereas spalling can only occur in the external lateral concrete cover. Then, the two Eqs. (33) and (34) can be expressed as a general function of time $t$ as follows:

$v_{E d}(t)=\frac{\theta_{\mathrm{QP}}}{2}+0.85 \cdot \gamma_{R d} \cdot[1+\rho(t)] \cdot \omega(t) \cdot \frac{h}{L}$,

$v_{R d}(t)=0.9 \cdot \delta \cdot \frac{h}{s_{e f f}} \cdot \rho_{s}(t) \cdot \omega(t) \cdot \overline{\overline{\operatorname{ctg} \beta(t)}}$

where the strut angle can be determined through Eq. (31)

$$
\begin{aligned}
\overline{\overline{\operatorname{ctg} \beta}} & =\sqrt{\frac{1}{2} \cdot \frac{A_{s, b}(t)}{A_{s}(t)} \cdot \frac{b(t) h f_{c d}}{A_{s, b} f_{s d}} \cdot \frac{s_{\text {eff }}}{h}-1} \\
& =\sqrt{\frac{1}{2} \cdot \frac{s_{\text {eff }}}{h} \cdot \frac{1}{\rho_{s}(t) \cdot \omega} \cdot \frac{b(t)}{b}-1} \leqslant 2.5 .
\end{aligned}
$$

and taking into account the time evolution of $\omega(t)$ and $\rho_{w}(t)$ due to corrosion and considering the effect of cover cracking and spalling on the effecting section width $b(t)$ which controls the values of the strut slope angle $\beta(t)$. Particularly, the current value of the beam section width can be determined as

$b(t)=b-x_{\text {loss }, c}(t)$

making use of the definition of $x_{\text {loss, }}(t)$ provided by Fig. 3 and described through Eq. (13).

Thus, the ductile-to-brittle transition occurrence can be, in principle, described by the following limit state equation:

$g_{d b}(t)=v_{R}(t)-v_{E}(t)$

where $v_{E}(t)$ and $v_{R}(t)$ are the stochastic processes whose design value at time thas been denoted as $v_{E d}(t)$ and $v_{R d}(t)$ in Eqs. (35) and (36), respectively. As a matter of principle, full statistical analysis should be carried out to determine the probability of brittle failure (i.e., the probability of having $g_{d b}(t)<0$ ) taking into account the natural randomness which affects the relevant material properties and the uncertainties related to the simplified nature of the models adopted for describing degradation phenomena in concrete members.

However, for the sake of simplicity, the present paper proposes a safety check inspired to the typical Level 2 methods of fib bulletin 34 (2006), namely a "Partial Factor Design Approach" carried out according to the provisions of EN 1992-1-1:2005 [4] and assuming the respective characteristic values (namely, the 95th percentiles) proposed in [9] for the parameters used in the various degradation models outlined in Section 2. Thus, according to the Partial Factor
Design Approach summarised in the latter document, a design value, $a_{d}$, for the concrete cover will be defined as:

$a_{d}=a-\Delta a$

where $a$ is the nominal value and $\Delta a$ is the safety margin (the value of $\Delta a=10 \mathrm{~mm}$ is used herein [9]). The value $a_{d}$ is considered for defining the initiation time and detection of the depassivation limit state as well as the residual capacity once spalling has occurred in concrete cover. The relevant parameters will be estimated as characteristic values taking into account the corresponding statistical information reported in Section 2. Then, the safety check against the possible limit state of brittle failure (Eq. (39)) can be performed by comparing the time evolution of the design values $v_{E d}(t)$ and $v_{R d}(t)$ determined by applying the partial safety factors proposed by [4] and adopted at the design stage.

\section{Parametric analysis}

This section describes the results of a parametric analysis aimed at comparing the time evolution of $v_{E d}(t)$ and $v_{R d}(t)$ defined in (33) and (34) of Section 3, taking account the effect of degradation phenomena discussed in Section 2. The analysis focuses on examining the four relevant exposure classes XC1, XC2, XC3 and XC4 defined in EN 1992-1-1:2005 [4]. For such classes, EN 206 (2006) [5] provides designers with "deemed-to-satisfy" rules consisting of:

- maximum water/cement ratio;

- minimum concrete cover;

- minimum cement content.

The limit values proposed for the above exposure classes are summarised in Table 3. Since the first two properties are considered in the models for simulating the time evolution of the relevant degradation phenomena proposed in Section 2, the corresponding limit values reported in Table 3 are considered in the following analyses. Thus, for each class, the aforementioned limit values of both $\mathrm{w} / \mathrm{c}$ ratio and concrete strength are assumed as material properties, with the aim of understanding whether they guarantee the required safety levels in terms of brittle failure avoidance or not.

Moreover, since several parameters play a role and have even cross-influences on both stress/strength parameters and degradation-related quantities, the proposed parametric analysis, though aiming at covering the wider possible parametric field, will be based on keeping the following numerical values constant:

$-\gamma_{R d}=1.0$, as assumed for structures in the so-called "Ductility Class B" in EN 1998-1-1:2005 [2];

$-\phi=16 \mathrm{~mm}$ is assumed for longitudinal bars and $\phi_{s}=8 \mathrm{~mm}$ for stirrups, as these values are rather common in practical applications;

$-t_{c}=7$ days and $\mathrm{RH}_{\text {real }}=45 \%$ are assumed and kept constant, even though the latter could be variable for the three exposure classes $\left(\mathrm{RH}_{\text {real }}\right.$ is obviously irrelevant in XC1);

Regarding the other parameters, the analysis starts from a reference case characterised by the following set of numerical values, which can be deemed representative of common practical cases:

Table 3

Deemed-to-satisfy rules for durability of concrete members in classes XC [5].

\begin{tabular}{lllll}
\hline Property & XC1 & XC2 & XC3 & XC4 \\
\hline Maximum w/c & 0.65 & 0.60 & 0.55 & 0.50 \\
Minimum concrete strength & $\mathrm{C} 20 / 25$ & $\mathrm{C} 25 / 30$ & $\mathrm{C} 30 / 37$ & $\mathrm{C} 30 / 37$ \\
Minimum cement content $\left(\mathrm{kg} / \mathrm{m}^{3}\right)$ & - & 260 & 280 & 280 \\
\hline
\end{tabular}


$-\theta_{Q P}=0.10$

$-\rho=1.00$

$-\omega=0.30$

$-\omega_{s}=0.015$

$-\lambda=10$

$-\delta=0.95$.

Moreover, the following values are considered for the parameters needed to apply the carbonation model outlined in subsection 2.1:

$-\mathrm{RH}_{\text {real }}=45 \%$, in Eq. (2);

$-t_{c}=7$ days, in Eq. (3);

- cement type CEM III/B 42.5 to assume the parameters reported in Table 1 and involved in Eq. (4);

- ToW $=0.0548$, namely 20 rainy days in 1 year (Eq. (5)).

First, the analyses address the time evolution of $v_{E d}(t)$ and $v_{R d}(t)$ defined in (33) and (34) for the reference case under consideration.
The four carbonation-related exposure classes were considered and, for each of these classes, the above mentioned "deemedto-satisfy" rules in terms of maximum $\mathrm{w} / \mathrm{c}$ ratio and minimum concrete strength (Table 3 ) are considered to select the relevant material properties. Then, the influence of some parameters chosen from the ones listed above is investigated to understand their possible effects on the degradation phenomena and their consequences in terms of possible failure mode. The flow-chart represented in Fig. 5 describes the procedure implemented to investigate the time evolution of $v_{E d}$ and $v_{R d}$.

\section{Results and comments}

The first results presented in this section deal with the evolution of the two relevant quantities $v_{E d}$ and $v_{R d}$ expressed by (33) and (34), respectively, for the reference RC beam, whose parameters are listed at the end of Section 4.

Fig. 6 confirms that in the case of "dry" environmental conditions (XC1), no degradation occurs and the values of $v_{E d}$ and $v_{R d}$

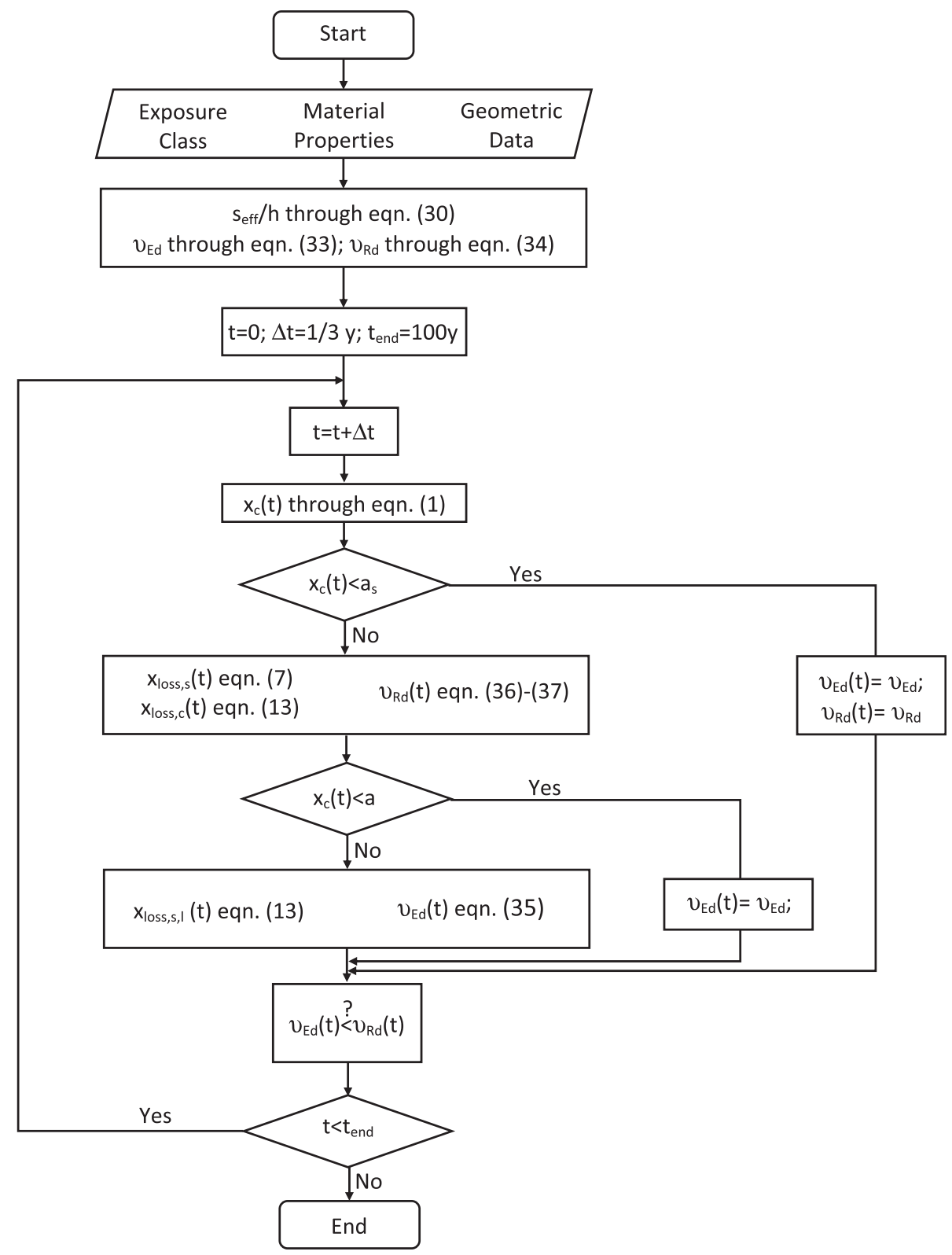

Fig. 5. Flow-chart of the analysis procedure. 
keep unchanged during the whole observation time, which is conventionally taken at 100 years $[2,4]$.

A significantly different result is obtained in the case of "wet, rarely dry" environments (XC2), as the safety margin about the shear over-strength vanishes in about 30 years (Fig. 7). Thus, this result casts a new and concerning light on the actual safety level of seismic resistant structures built in aggressive environments, as the ductile behaviour of members (guaranteed, in principle, by applying the Capacity Design approach) can vanish during the structure service life due to degradation phenomena and the possible brittle failure of members under a possible earthquake can lead to an undesired premature failure.

Less concerning results are obtained from a similar analysis carried out on structures in "moderate humidity" environment (XC3). Fig. 8 shows that the safety margin imposed at the design stage against a possible brittle failure does not fall below the reliability levels foreseen by structural codes, as the actual design shear strength is always higher than the corresponding shear stresses, at least in 100 years, which is the longest service life duration possibly assumed for important RC structures, such as those belonging to strategic facilities [2].

However, considerations similar to the ones drawn out for XC2 emerge for members in "Cyclic wet and dry" environments (XC4), as Fig. 9 shows a possible transition from ductile-to-brittle failure mode is expected in about 35 years, which is less than the usual service life assumed even for ordinary buildings.

Thus, the above mentioned figures point out the fact that the safety margin against brittle failure modes can significantly shrink during the service life of seismically designed RC beams as a result of the environment-induced material degradation phenomena. The

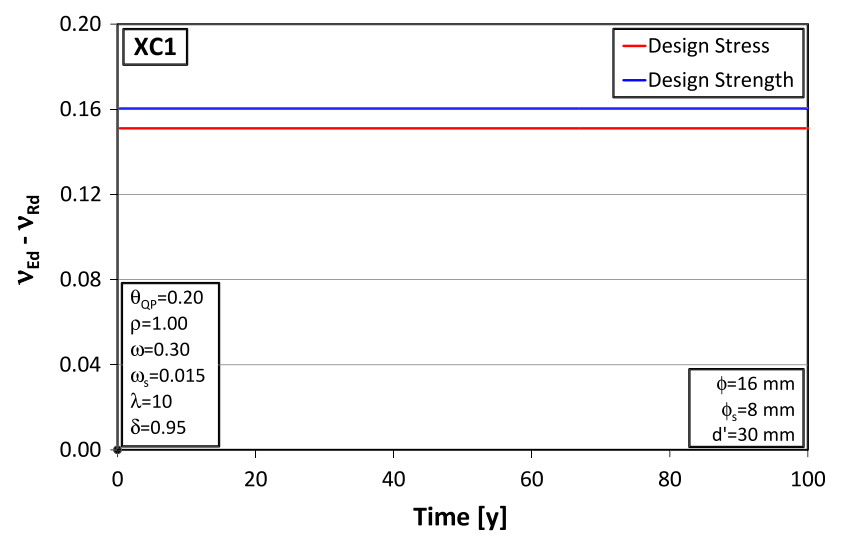

Fig. 6. Time evolution of shear stress and strength: exposure class XC1.

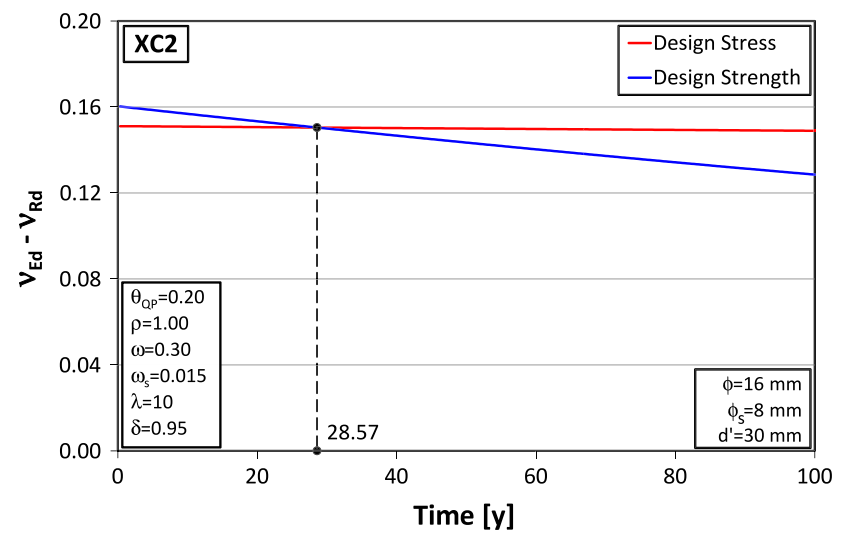

Fig. 7. Time evolution of shear stress and strength: exposure class XC2.

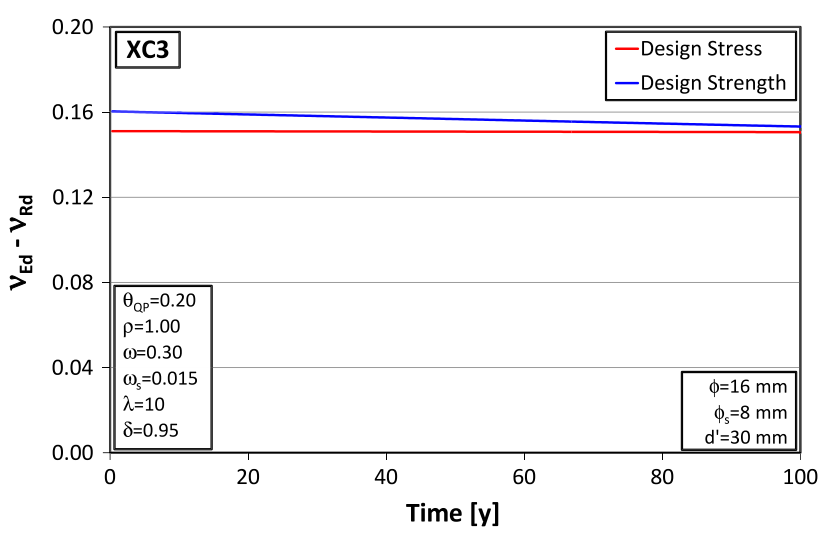

Fig. 8. Time evolution of shear stress and strength: exposure class XC3.

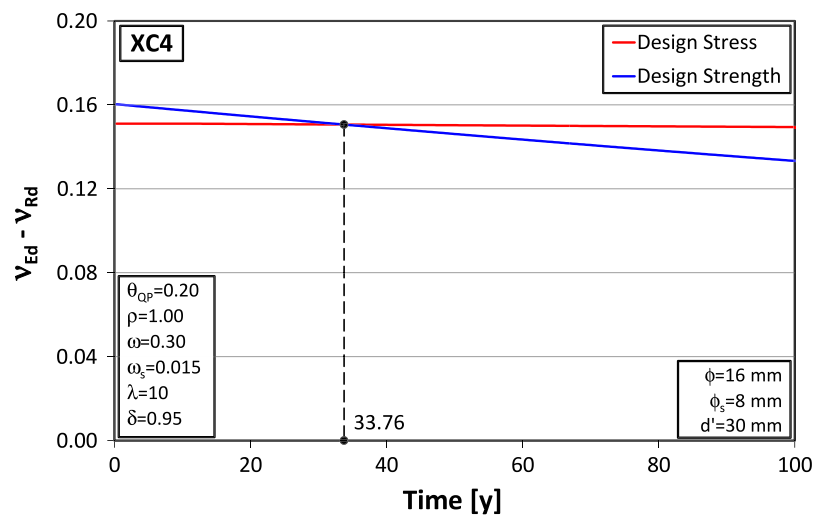

Fig. 9. Time evolution of shear stress and strength: exposure class XC4.

time taken for that margin to fall below the code requirements is conceptually represented by the intersection of the two curves depicted in such figures: this will be defined as "time for ductile-tobrittle transition" and will be denoted by the symbol $t_{D B}$.

As expected, class XC2 and XC4 result in the highest effects induced by material degradation, whereas XC1 and XC3 (due to different reasons) do not lead to possible brittle failures, at least during the service life of seismically designed members. Since the first two exposure classes are the most challenging ones for $\mathrm{RC}$ members, the following analyses only focus on members in environment class XC2 and XC4. These analyses pave the way to clarify the influence of the following parameters (whose values have been kept constant so far) on the possible ductile-to-brittle transition and $t_{D B}$ :

- the longitudinal reinforcement, represented by the parameter $\omega$ defined by Eq. (27);

- the concrete cover a represented in Fig. 4;

- the transverse load $q_{\mathrm{QP}}$, represented by the dimensionless quantity $\theta_{Q P}$ defined by Eq. (23).

The results presented in the following figures refer to analyses carried out by varying one of the above mentioned parameters, while keeping the remaining ones constant to the values listed in Section 4 to identify the "reference case". Moreover, in some cases, the influence of different values of the $\mathrm{w} / \mathrm{c}$ ratio (which has been adopted so far according to the limit values reported in Table 3) and seismic over-strength ratio $\gamma_{R d}$ are also considered. All the analyses are carried out under the assumption that the number of longitudinal bars is $n_{b}=5$ and only the outer one (in both bottom and top layers) is possibly affected by corrosion. 


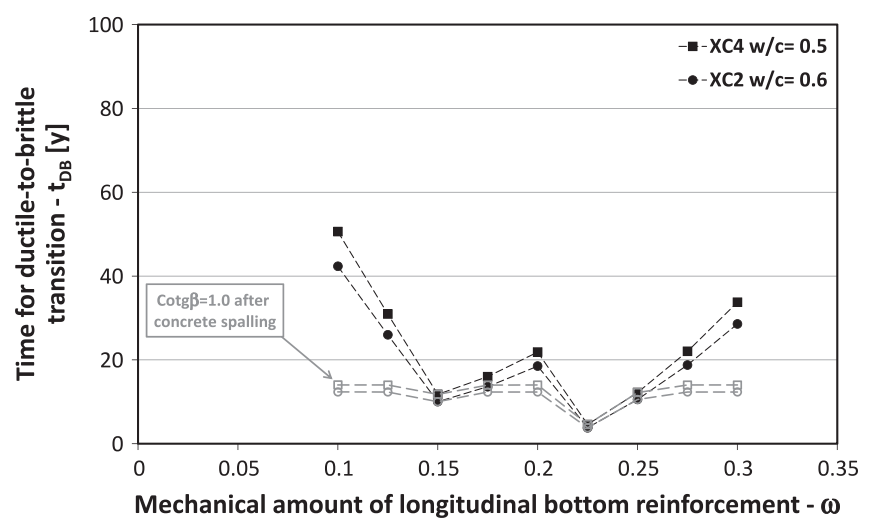

Fig. 10. Effect of the amount of longitudinal reinforcement.

Fig. 10 describes the influence of the amount of longitudinal steel reinforcement represented by the dimensionless parameter $\omega$ ranging between 0.10 and 0.30 , as often occurs in real RC beam section. Fig. 10 shows that $t_{D B}$ is always shorter than the reference life-time for ordinary structures for both XC2 and XC4 and, then, materials degradation phenomena significantly reduces the level of safety initially established as a result of the application of the Capacity Design principles. The black lines reported in Fig. 10 refer to the application of the shear strength model described in Section 3, based on the variable inclination of the equivalent strut described by Eq. (37). However, as a matter of fact, material degradation and, particularly, the loss of bond which is expected to occur as a result of both cracking and spalling of the concrete cover can affect the internal redistribution mechanisms leading to the aforementioned angle of the equivalent strut. Although no well-established model is currently available to evaluate the shear strength in RC members with corroded bars, a safe estimation of $v_{R d}(t)$ in such conditions can be reasonably obtained by assuming $\beta=45^{\circ}(\operatorname{cotg} \beta=1)$ in Eq. (36) [18]. The dashed grey lines in Fig. 10 reports the results obtained under such an assumption and demonstrates that environment-induced degradation phenomena can be even more detrimental for RC members.

However, since, on the one hand, the aforementioned assumption for determining shear strength of RC members with corroded bars is not fully established, and, on the other hand, this paper is mainly intended at understanding the possible effect of material degradation even under the best scenario, the following evaluation are simply based on the variable strut angle model as described in Eq. (36).

Under this assumption, further information on the effect of material degradation can be derived from Fig. 11, which reports the variation of $t_{D B}$ depending on a possible variation in the concrete cover $a$ (Fig. 4 ) in the cases of XC2 and XC4 exposure classes. Almost constant values of $t_{D B}$ were obtained for low values of concrete cover (between $20 \mathrm{~mm}$ and $25 \mathrm{~mm}$ ) as a result of the constant safety margin, $\Delta a$, assumed in the partial safety factor calculations according to Eq. (40). Such a constant branch means that corrosion is supposed to begin at a very early stage due to a zero design value of concrete cover $\left(a_{d}\right)$ for stirrups. Then, once the cover of longitudinal bars achieves a sufficient value (i.e. $a>26-28 \mathrm{~mm}$ ) the values of $t_{D B}$ increase, mainly as a result of the delayed initiation of corrosion due to longer depassivation times for thicker concrete covers. In this regard, the results obtained for the member exposed to XC4 class are characterised by a higher sensitivity to the concrete cover, as in that case of a maximum $\mathrm{w} / \mathrm{c}$ ratio lower than the corresponding one in XC2 is considered in the present analyses (see Table 3). In fact, Fig. 12 confirms that longer values of $t_{D B}$ could be obtained by reducing the values

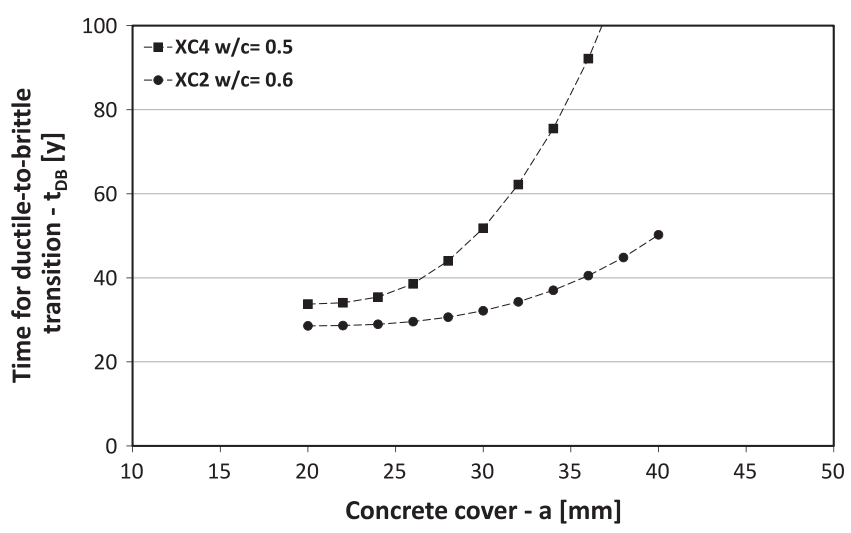

Fig. 11. Effect of the amount of concrete cover.

of $\mathrm{w} / \mathrm{c}$ ratio for the exposure class $\mathrm{XC2}$, as the limit value provided for general purposes by [5] (namely, $x / c=0.6$ ) clearly does not guarantee the design shear over-strength provided throughout the service life of the structure. Similar considerations can be drawn out by observing the results reported in Fig. 13 for members in exposure class XC4. As a matter of principle, values of w/c and concrete cover, which guarantee a value of $t_{D B}$ equal to (or longer than) the design service life of the structure under consideration can be chosen to guarantee ductile failure of members under any environmental condition.

An alternative solution to increase the values of $t_{D B}$ without changing the $\mathrm{w} / \mathrm{c}$ ratio can be obtained by assuming higher values of the over-strength factor $\gamma_{R d}$. Fig. 14 shows the variation of $t_{D B}$ obtained in case of XC2 (for $\mathrm{w} / \mathrm{c}=0.6$ according to the mentioned limits provided by [5]) induced by adopting three different values of $\gamma_{R d}$. Particularly, it could be observed that the increase of $\gamma_{R d}$ from 1.0 to 1.1 results in a significant increase for $t_{D B}$, which is often longer than the usual service life of ordinary structures (i.e., 50 years). Even more significant increases of $t_{D B}$ can be achieved by means of a higher $\gamma_{R d}$ value in the case of XC4 (Fig. 15).

In principle, $t_{D B}$ is influenced by the relationship between bending moments (which control shear stresses in Eq. (15)) and shear strength. Since the value of transverse loads $\theta_{\mathrm{QP}}$ plays a significant role in controlling shear forces, Fig. 16 shows the actual influence of such a parameter on the values of $t_{D B}$ : it points out that $t_{D B}$ falls far below the reference life time of 50 years for relevant values $\theta_{Q P}$ (and, then, $q_{Q P}$ ) represented by the corresponding non-dimensional quantity $\theta_{Q P}$ in the neighbourhood of 0.15 . In this regard, it is worth highlighting that value of $\theta_{Q P}$ ranging between 0.10 and 0.20 are the most common in practical applications.

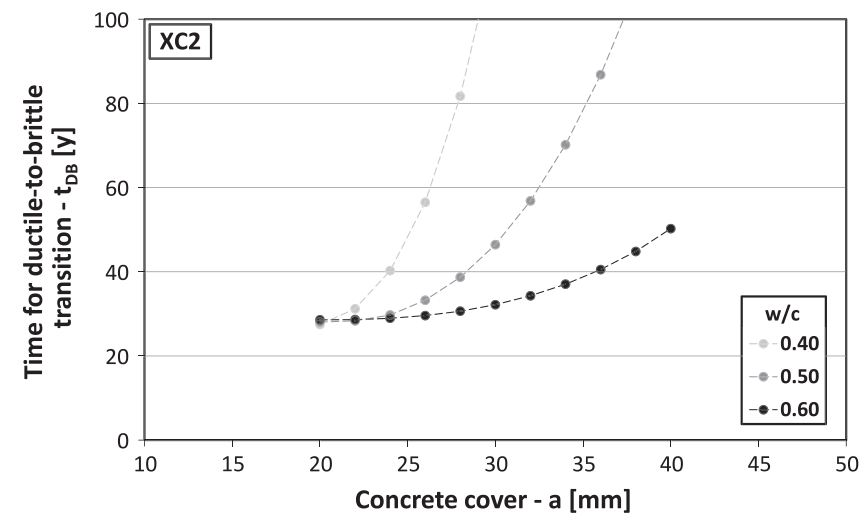

Fig. 12. The effect of $w / c$ ratio on the possible ductile-to-brittle transition (XC2). 


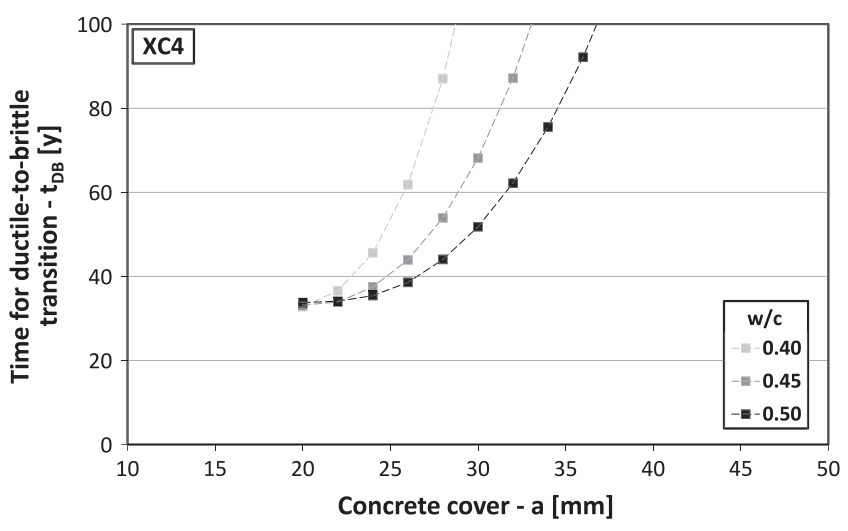

Fig. 13. The effect of $w / c$ ratio on the possible ductile-to-brittle transition (XC4).

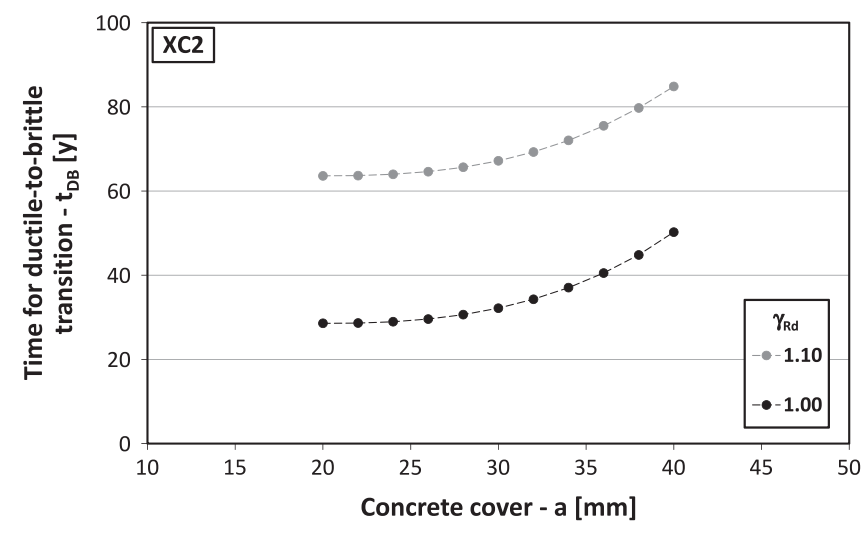

Fig. 14. The effect of the design over-strength ratio $\gamma_{R d}$ on the possible ductile-tobrittle transition (XC2).

Finally, the above considerations provide a series of quantitative measures of $t_{D B}$ and, indirectly, of the possible effect of materials degradation phenomena on the safety margin against brittle failure. Since $t_{D B}$ fell quite often below the usual service life duration for common buildings (i.e. 50 years) the above simplified analyses cast a concerning light on the actual safety levels which characterise newly designed structures in seismic areas, even in mildly aggressive environment conditions such as those just characterised by carbonation-induced degradation phenomena.

\section{Concluding remarks}

This paper presented the results of a study aimed at investigating the possible time evolution of the safety margin against shear over-strength imposed on RC members by applying the Capacity Design principles to face seismic actions. The environment-induced degradation phenomena can generally affect the integrity of structural members and, particularly, reduce the shear strength as a result of the premature degradation of steel stirrups, which are protected by concrete covers thinner than those available for longitudinal bars.

The multidisciplinary nature of the knowledge required to approach the above mentioned problem was clearly emphasised. Thus, a simplified, though up-to-date, set of models was firstly outlined to provide readers with an operational protocol to introduce the effects of material degradation in the usual seismic analyses, which are more familiar to the structural engineer. Then, the article focused on the problem of detecting the possible transition from ductile to brittle failure mode induced by steel reinforcement degradation in RC beams. The obtained results can be summarised as follows:

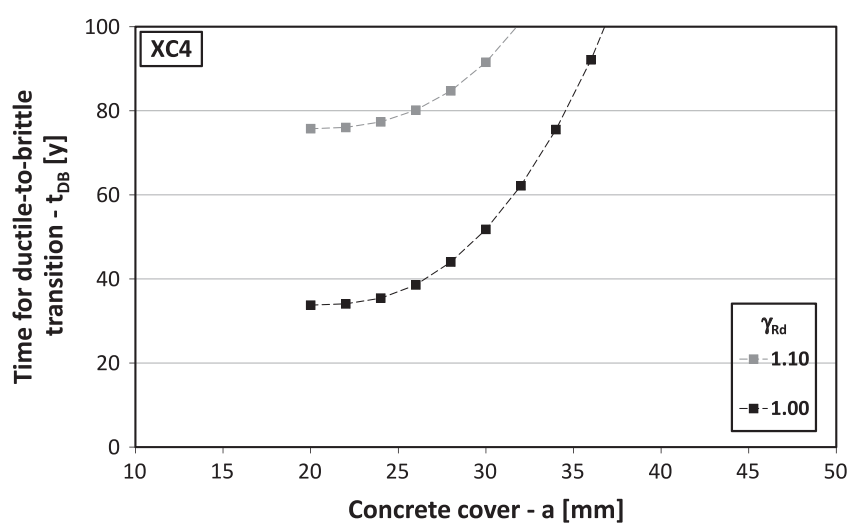

Fig. 15. The effect of the design over-strength ratio $\gamma_{R d}$ on the possible ductile-tobrittle transition (XC4).

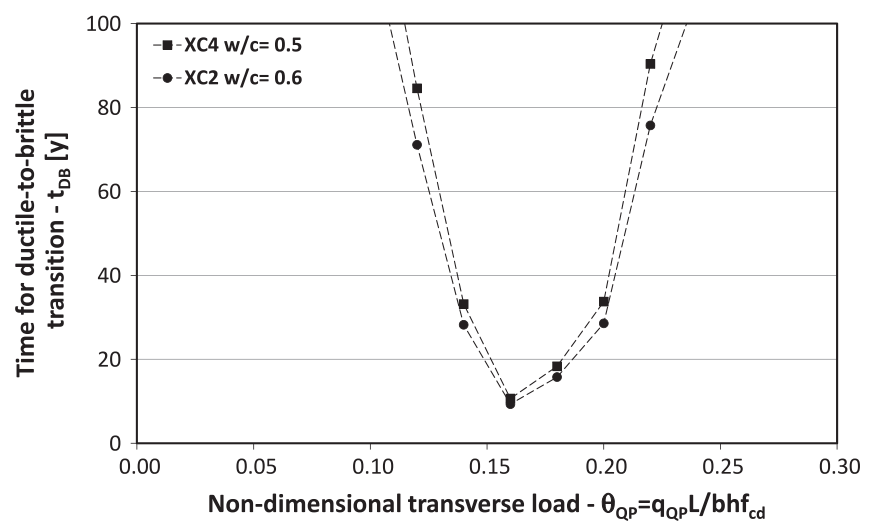

Fig. 16. Role of the transverse load on the possible ductile-to-brittle transition.

- the limitations in terms of maximum $\mathrm{w} / \mathrm{c}$ ratio and minimum concrete strength provided by EN 206 [5] to preserve the durability of RC structures do not generally guarantee that the failure mode hierarchy (i.e. bending failure precedes shear failure) during the service life of RC beams in seismic areas is preserved;

- particularly, within the exposure classes in which carbonationinduced phenomena are relevant, the classes XC2 and XC4 led to the shortest values of expected time $t_{D B}$ for the ductile-tobrittle transition in RC beams;

- shorter $t_{D B}$ values were determined for both classes in case of higher amount of longitudinal steel reinforcement;

- the role played by the concrete cover on $t_{D B}$ emerged clearly;

- a relationship between $t_{D B}$ and $\mathrm{w} / \mathrm{c}$ ratio and concrete cover $a$ has been established, which can be used as a design tool for choosing the $\mathrm{w} / \mathrm{c}$ and a depending on the design service life;

- an alternative solution for preserving the safety margin against the possible occurrence of brittle shear failure under seismic action can be clearly achieved by increasing the initial shear $\gamma_{R d}$ over-strength values;

- static transverse loads applied on the beam emerged as a relevant parameter in the possible transition from a ductile bending failure to a brittle shear failure due to the environment-induced degradation of materials.

Finally, these observations point out that material degradation phenomena occurring in RC frames can significantly affect their seismic safety. In fact, the premature corrosion of steel stirrups can significantly reduce the initial value of shear overstrength resulting by the application of the principle inspiring the Seismic 
Capacity Design approach. However, although the results reported in this study are based on well-established models for material degradation, the assessment of shear over-strength is based on the simplified semi-probabilistic approach based on the usual partial safety factor method widely adopted in design codes. Furthermore, only the carbonation-induced degradation phenomena were considered in this study, whereas the chloride-induced carbonation, which is harder to model but can potentially have more detrimental effects on the structure, has not been considered. Thus, the development of a more accurate analysis based on a full probabilistic approach to quantify the structural safety, as well as the extension of this study to a wider range of degradation phenomena (i.e. those induced by chloride-penetration) are planned as the next stages of the present research.

\section{Acknowledgements}

This study is part of a scientific collaboration developed within the framework of the NERA Project (EC Project Number 262330) whose financial support is gratefully acknowledged.

\section{References}

[1] Paulay T, Priestley MJN. Seismic design of reinforced concrete and masonry buildings. New York, USA: Wiley; 1992.

[2] EN 1998-1: 2005, Eurocode 8: design of structures for earthquake resistance Part 1: General rules, seismic actions and rules for buildings, March 2005.

[3] DuraCrete. Modelling of degradation, Document BE95-1347/R4-5; 2000a.
[4] EN 1992-1-1: 2005, Eurocode 2: design of concrete structures - general rules and rules for buildings, November 2005.

[5] EN 206-1: 2006, Concrete - Part 1: specification, performance, production and conformity, March 2006.

[6] Bertolini L, Elsener B, Pedeferri P, Polder R. Corrosion of steel in concrete prevention, diagnosis repair. Wiley; 2004 [ISBN: 3-527-30800-8].

[7] Stewart MG, Wang X, Nguyen MN. Climate change impact and risks of concrete infrastructure deterioration. Eng Struct 2011;33(4):1326-37.

[8] Berto L, Vitaliani R, Saetta A, Simioni P. Seismic assessment of existing RC structures affected by degradation phenomena. Struct Saf 2011;31(4):284-97.

[9] fib. Model code for service life design. Bulletin no. 34; 2006.

[10] DuraCrete. Final technical report: general guidelines for durability design and redesign. Document BE95-1347/R17; 2000b.

[11] Matsuzawa K, Kitsutaka Y, Tsukagoshi M. Effect of humidity on rate of carbonation of concrete exposed to high-temperature environment. In: Proceedings of the international symposium on the ageing management \& maintenance of nuclear power plants, May 27-28, Tokyo (Japan); 2010. p. 109-14.

[12] Abosrra L, Ashour AF, Youseffi M. Corrosion of steel reinforcement in concrete of different compressive strengths. Constr Build Mater 2011;25(10):3915-25.

[13] Tuutti K. Corrosion of steel in concrete. Stockholm: Swedish Cement and Concrete Research Institute. CBI Research No. Fo. 4:82; 1982.

[14] DARTS. Durable and reliable tunnel structure: data, European commission, growths 2000. Contract G1RD-CT-2000-00467, Project GrD1-25633; 2004.

[15] Gonzales JA, Andrade C, Alonso C, Feliu S. Comparison of rates of general corrosion and maximum pitting penetration on concrete embedded steel reinforcement. Cem Concr Res 1995;25(2):257-64.

[16] Chen Ou Y, Lan Tsai L, Chen H-H. Cyclic performance of large-scale corroded reinforced concrete beams. Earthq Eng Struct Dyn 2011;41(4):593-604.

[17] Amleh L, Ghosh A. Modeling the effect of corrosion on bond strength at the steel-concrete interface with finite-element analysis. Can J Civ Eng 2006;33:673-82.

[18] CONTECVET. A validated users manual for assessing the residual service life of concrete structures - manual for assessing corrosion-affected concrete structures. GEOCISA \& Torroja Institute, Madrid (ES); 2001. 